\title{
Development and validation of the Domestic Violence during Quarantine Scale (DVQS)
}

\author{
Reza Ghanei Gheshlagh ${ }^{1} \cdot$ Kamel Abdi $^{2} \cdot$ Abbas Ebadi $^{3} \cdot$ Borhan Moradveisi $^{4} \cdot$ Seyedeh Esmat Hosseini ${ }^{5}$. \\ Hosein Zahednezhad ${ }^{6}$ (D)
}

Received: 18 October 2020 / Accepted: 17 May 2021 / Published online: 8 June 2021

(C) The Author(s), under exclusive licence to Springer-Verlag GmbH Germany, part of Springer Nature 2021

\begin{abstract}
Background Domestic violence is a common health problem that often affects women's mental health. Although domestic violence may not be reported during quarantine, it may increase due to increased restrictions. Therefore, the goal of the present study was to develop and validate the Domestic Violence during Quarantine Scale (DVQS) on a sample from Iran.

Methods Two hundred and three Iranians participated in this study and completed online questionnaires. This cross-sectional and methodological study consisted of two phases. In the first phase, item pool generation and questionnaire design was carried out through literature review. In the second phase, psychometric properties were assessed via an exploratory factors analysis (EFA). Internal consistency was examined by Cronbach's alpha coefficient and McDonalds' Omega.

Results In the EFA, three factors, including humiliation (seven items), threatening (six items), and restriction (four items) were extracted that together explained $64.4 \%$ of the variance of domestic violence during quarantine. Using Cronbach's alpha coefficient, the internal consistency of humiliation, threatening, and restriction was found to be $0.90,0.896$, and 0.76 respectively, and an alpha of 0.927 was found for the total scale. In addition, using McDonalds' Omega, internal consistencies of 0.82, 0.84, and 0.78 were found for the three factors respectively.

Conclusion The DVQS has good validity and reliability; therefore, it can be used in future studies.
\end{abstract}

Keywords Validation $\cdot$ Domestic violence $\cdot$ Quarantine $\cdot$ Domestic abuse

Hosein Zahednezhad

zahednezhadhosein@gmail.com

Reza Ghanei Gheshlagh

rezaghanei30@gmail.com

Kamel Abdi

kamel.abdi@komar.edu.iq

Abbas Ebadi

Ebadi1347@yahoo.com

Borhan Moradveisi

b.moradvaesi@yahoo.com

Seyedeh Esmat Hosseini

esmat.hosseini_110@yahoo.com
1 Spiritual Health Research Center, Research Institute for Health Development, Kurdistan University of Medical Sciences, Sanandaj, Iran

2 Nursing Department, Faculty of Medicine, Komar University of Science and Technology, Sulimaniya City, Kurdistan Region, Iraq

3 Behavioral Sciences Research Center, Life Style Institute, Nursing Faculty, Baqiyatallah University of Medical Sciences, Tehran, Iran

4 Cancer and Immunology Research Center, Research Institute for Health Development, Kurdistan University of Medical Sciences, Sanandaj, Iran

5 School of Nursing and Midwifery, Shahid Beheshti University of Medical Sciences, Tehran, Iran

6 Department of Psychiatric Nursing and Management, School of Nursing \& Midwifery, Shahid Beheshti University of Medical Sciences, Tehran, Iran 


\section{Background}

The fast spread of coronavirus led to a global pandemic and anxiety throughout the world; the World Health Organization (2019) recommended social distancing and other restrictions to reduce the number of new infections. Stay-at-home policies have been widely applied to reduce the impact of the virus in more than 142 countries (Agüero 2021).

These restrictions have had negative, unwanted outcomes, such as isolation and loneliness, economic challenges, closure of businesses and schools, and loss of jobs (Bradbury-Jones and Isham 2020). The COVID-19 epidemic and quarantine provide conditions for the perpetration, intensification, and acceleration of various forms of violence against women and children around the world (Abuhammad 2021). The COVID19 epidemic has led to an increase in domestic violence worldwide. This situation is described as a "double epidemic" and is considered a new crisis. In one of the rural areas of Hubei province (Qianjiang), the rate of domestic violence in the COVID-19 epidemic reported to the police had doubled compared to 2019 (Zhang 2020). In the UK, calls to the domestic violence helpline rose $25 \%$ in the first week after lockdown measurement. In the United States, during the COVID-19 pandemic, the number of calls for help for domestic violence increased by $10.2 \%$ (Leslie and Wilson 2020).

Recently, researchers added domestic violence, as a public health concern, to complications of the covid-19 pandemic, because it has spread like an opportunistic infection during the COVID-19 quarantine. Violence against women refers to a pattern of coercive control, including physical, sexual, or mental abuse against one's sexual partner; in most cases, the perpetrator is a man and the victim is a woman (KoziolMcLain et al. 2001). In February 2020, about 162 cases of domestic violence were reported in Jingzhou, China, with women being the victims in more than $94 \%$ of cases (Zhang 2020). Despite the existing laws on domestic violence, this problem is common in most countries with any culture, race, ethnicity, or socioeconomic status, and millions of women around the world are affected by this problem (Azadarmaki et al. 2016). In the early days of the COVID-19 pandemic, emergency calls related to domestic violence increased by 39\% and 53\% in Argentina and Mexico respectively. There is a link between domestic violence and disability, murder, pregnancy complications, major depressive disorder, suicide, alcohol or drug use, and financial losses (Koziol-McLain et al. 2001). The prevalence of violence against women in Iran is high. The results of meta-analysis of Hajnasiri et al. (2016) demonstrated that the prevalence of domestic violence in Iran is $66 \%$. Another meta-analysis showed that the prevalence of emotional, physical, and sexual violence against Iranian women was $59 \%, 45 \%$, and $32 \%$ respectively (Hajnasiri et al. 2017). In the first week of quarantine in France, domestic violence increased by $32 \%$. During the first 2 weeks of quarantine, domestic violence increased by $60 \%, 18 \%$, and $250 \%$ in Argentina, Brazil, and Colombia respectively. In Australia, there has an increase up to $75 \%$ in internet searches to seek help by victims of domestic violence. Domestic violence seems not to be limited to a specific country and has been rising all over the world. In other words, these reports only show the tip of the iceberg, because many victims of domestic violence may have not been able to report it due to being isolated at home (Campbell 2020).

The incidence of domestic violence has increased during the COVID-19 quarantine, because victims are forced to isolate themselves at home, and are potentially subject to violence. Domestic violence is a hidden problem, because it is often not reported by women due to cultural norms, financial problems, fear of losing their children, lack of trust in health officials, and low awareness (Azadarmaki et al. 2016). Although violence against women has a long history and is not limited to the COVID-19 pandemic, the nature and type of violence perpetrated in this period may be different from previous periods. Due to the lockdown measurements, most families are forced to spend more time together; differences in tastes can lead to tension and eventually violence. Concepts change over time, and are sometimes influenced by the culture and context of societies, so it is necessary to review their measurement and use more appropriate tools to measure them. The existence of a tool to measure domestic violence in the Corona pandemic allows researchers to further investigate this issue, which could be of interest to health officials. On the other hand, as far as we know, there is no instrument available in Iran to assess all aspects of this problem according to the specific culture and socioeconomic status of this country. Therefore, the present study is aimed at developing and validating an instrument to assess domestic violence during quarantine in Iran.

\section{Methods}

This methodological study was conducted in two phases: first, a literature review was carried out for item pool generation and designing the instrument; and second, a quantitative approach was taken to psychometric evaluation.

\section{First phase: item generation and instrument design}

To define the theoretical framework of domestic violence, a broad literature review was conducted based on national and international databases and reputable sites. Thence, an initial item pool was developed and then revised multiple times during consensus discussion among the authors. 


\section{Second phase: psychometric evaluation}

The initial draft of the questionnaire had 45 items with a 5point Likert scale. The responses showed the frequency of violence during quarantine and were as follows: Never, 1 to 2 times, 3 to 5 times, 6 to 10 times and more than 10 times.

\section{Samples and setting}

The participants were Iranian married women, chosen via convenience sampling from April to June 2020. Inclusion criteria were: age over 18 years, and being married. The length of the quarantine period was the same for all people, but it is unclear how well they complied with these rules. According to the rule of thumb, the sample size was determined based on the number of items. It is usually recommended to select three to ten samples per item, so we selected 203 samples for the 17 item questionnaire (Kellar and Kelvin 2013).

The Domestic Violence tool was designed in Porsline (equivalent to Google Forms) and distributed to various groups via WhatsApp and Telegram. The duration of the online link was 1 month and after the link was deactivated, the data was collected. On the first page, the objectives of the study were clearly explained to the samples and they were asked to enter the next page by clicking on the "Continue" option and respond to the answers. Completing the online scale indicated the participant's consent to participate in the study. In addition, anonymity in data collection was ensured.

\section{Face validity}

Face validity was assessed in a qualitative and quantitative manner. At this stage, a questionnaire was sent to ten married women whose e-mails were available, and they were asked to read the questionnaire items and identify any vague items that were incomprehensible to them. For quantitative face validity and impact score assessment, the same women were asked to rate the importance of each item (frequency * importance) (Bolarinwa 2015).

\section{Content validity}

In order to assess content validity qualitatively, ten experts (professors in health education, nursing, psychology, midwifery, and psychiatry) examined the items in terms of use of appropriate phrases, compliance with grammar, and proper placement of terms. For content validity ratio (CVR), we applied Lawshe's method to assess how essential an item was for the questionnaire; the experts investigated each item based on a three-part spectrum as follows: is essential, is helpful but not essential, and is not necessary. Based on Lawshe's table, the items with CVR value of 0.62 or above were accepted (Lawshe 1975). In order to examine content validity quantitatively, the content validity index (CVI) was calculated; experts rated the relevancy of the items on 4-point Likerttype scale (not relevant, requiring overall revision, relevant but requiring brief revision, completely irrelevant) based on Waltz \& Bausell's recommendation. In order to calculate the CVI for each item, the total number of experts was divided by the number of experts who selected the response options of "completely relevant" or "relevant but requiring brief revision" for the respective item (Waltz et al. 2010). In addition, a CVI of 0.79 or higher was considered acceptable (Polit and Beck 2006).

\section{Data analysis}

Data analysis was performed using SPSS, version 16. Construct validity was assessed using exploratory factor analysis (EFA), and a sample size of 203 was selected (Kellar and Kelvin 2013). Maximun likelihood analysis with promax rotation was applied after conducting the Kaiser-Mayer-Olkin (KMO) index and Bartlett's test of sphericity (Nunnally and Bernstein 1994). KMO values closer to 1 indicate the adequacy of sample size for performing factor analysis; $\mathrm{KMO}$ values between 0.7 and 0.8 were considered good, and values between 0.80 and 0.90 were considered excellent (Sharif Nia et al. 2014). The number of extracted factors was determined based on eigenvalues (above 1) and scree plot. A loading value of 0.30 or higher was considered acceptable (Osborne 2008). Higher loading values better show the extracted factors (Vakili et al. 2012).

\section{Reliability}

Cronbach's alpha coefficient and McDonalds' Omega were used to examine internal consistency (Polit and Beck 2006); an alpha coefficient of 0.7 or higher is considered acceptable (Dilorio 2006). McDonalds' Omega was calculated based on the following formula: $\left.\left.\Omega=1-\llbracket a-\sum h_{i}^{\prime}\right] /[a+2 b]\right]$ where "a" is the number of factor items, " $h_{i}^{\prime}$ " is the total communality and " $\mathrm{b}$ " is the total factor loading of the factor (Dunn et al. 2014).

\section{Ethical considerations}

The ethics committee of Shahid Beheshti University of Medical Sciences approved this study (IR.SBMU.PHARMACY.REC.1399.258). Before starting the study, the study objectives were explained to the participants, and the participants were reassured that their personal information remained completely confidential. 


\section{Results}

\section{Descriptive data}

Domestic violence tool items were designed based on a review of questionnaires and articles and internal literature. The study sample included 203 women with a mean age of 38.59 \pm 8.77 years, with ages ranging from 19 to 67 years. The mean age of participants' husbands was $42.68 \pm 9.52$ years. Most of the participants $(76.4 \%)$ had college education, and the remainder had high school or middle school education; $90.6 \%$ of these women were married by their own choice and $9.4 \%$ were forced to marry, and about half of them (49.8\%) knew their husbands before marriage; $6.9 \%$ of the participants had had a previous marriage. The majority of participants (64\%) had a family with average socioeconomic status.

\section{Face and content validities}

On examination of face validity, minor modifications were made into four items, and several statements were rewritten. In terms of quantitative face validity, 11 items that had an impact score of less than 1.5 were removed and the remaining items remained for the next steps.

In CVR and CVI, 15 and 12 items were deleted, respectively, based on Lawshe's table (scores of less than 0.62) and Waltz \& Bausell's index (scores less than 0.79), and the rest of the items (17 items) were saved.

\section{Construct validity}

\section{Exploratory factor analysis (EFA)}

A KMO of 0.904 was found, and Bartlett's test of sphericity was significant $(p=0.001)$. According to the result, three factors, including physical violence (seven items), emotional violence (six items), and sexual violence and restriction (four items) with eigenvalues of 8.01, 1.84, and 1.10 were extracted that together explained $57.19 \%$ of the variance of domestic violence during quarantine (Fig. 1). The results of the exploratory factor analysis are presented in more detail in Table 1.

\section{Reliability}

Using Cronbach's alpha coefficient, the internal consistency of humiliation, threatening, and restriction was found to be $0.90,0.896$, and 0.76 respectively. In addition, using McDonalds' Omega, internal consistency estimates of 0.82 , 0.84 , and 0.78 were found for the three factors respectively.

\section{Discussion}

The goal of the present study was to develop and examine the psychometric properties of the Domestic Violence during Quarantine Scale (DVQS). In the EFA, three factors, including physical, emotional, and sexual with restriction were extracted. The oldest Iranian scale in this domain was focused on assessing physical, mental, and sexual abuse using 44 items (Ghahari et al. 2006). Given that like any other variable, violence is affected by changes in cultural values over time, it is always necessary to design new instruments to assess this variable. In addition, the Violence Against Women instrument (VAWI) that has been often used to assess domestic violence assesses three dimensions of violence, including psychological (four items), physical (six items), and sexual (three items) (World Health Organization 2005). Emotional violence has manifested itself in humiliation, and physical violence in the form of threatening behaviors. Coercive controlling violence is a type of emotional abuse that is accompanied by coercion, intimidation, and control, and sometimes physical violence (Ali and McGarry 2019; Kelly and Johnson 2008). This type of abuse was previously called patriarchal terrorism or intimate terrorism that is increased and intensified over time (Ansara and Hindin 2010; Ansara and Hindin 2011). The items of third dimension refer to this type of violence in which a wife is deprived of her necessary rights, and only one of the four items refers to sexual violence. This dimension of the DVQS had the lowest number of items, and showed unfair control by a man and a deprivation of a woman's necessary rights. Sometimes women show violent resistance against domestic violence that is called self-defense, female resistance, or battered women syndrome. This defense is often useless, and only makes the situation worse (Ali and McGarry 2019). Violent resistance seems not to be culture-bound, and is experienced as a natural reaction. The existing instruments assessing domestic violence seem to ignore this type of violence. The dimension of physical violence shows threatening with physical harm, and can result from female resistance, which is implicitly referred to in the DVQS.

A common type of domestic violence is situational couple violence that results from conflicts and arguments between partners, and seems not to increase over time. This type of violence often results from inability of a partner or both of them to manage anger or conflict that leads to physical violence (Kelly and Johnson 2008; Johnson 2006). During quarantine, couples spend more time together, and this increases the likelihood of tension due to different preferences. This type of violence often includes verbal insulting such as shouting, cursing, and accusations of infidelity (Kelly and Johnson 2008; Johnson 2006), and is consistent with the items of the emotional violence. The highest number of items was related to the dimension of emotional violence. This dimension refers to behaviors by a husband toward his wife such as 
Fig. 1 The scree plot for exploratory factor analysis
Scree Plot

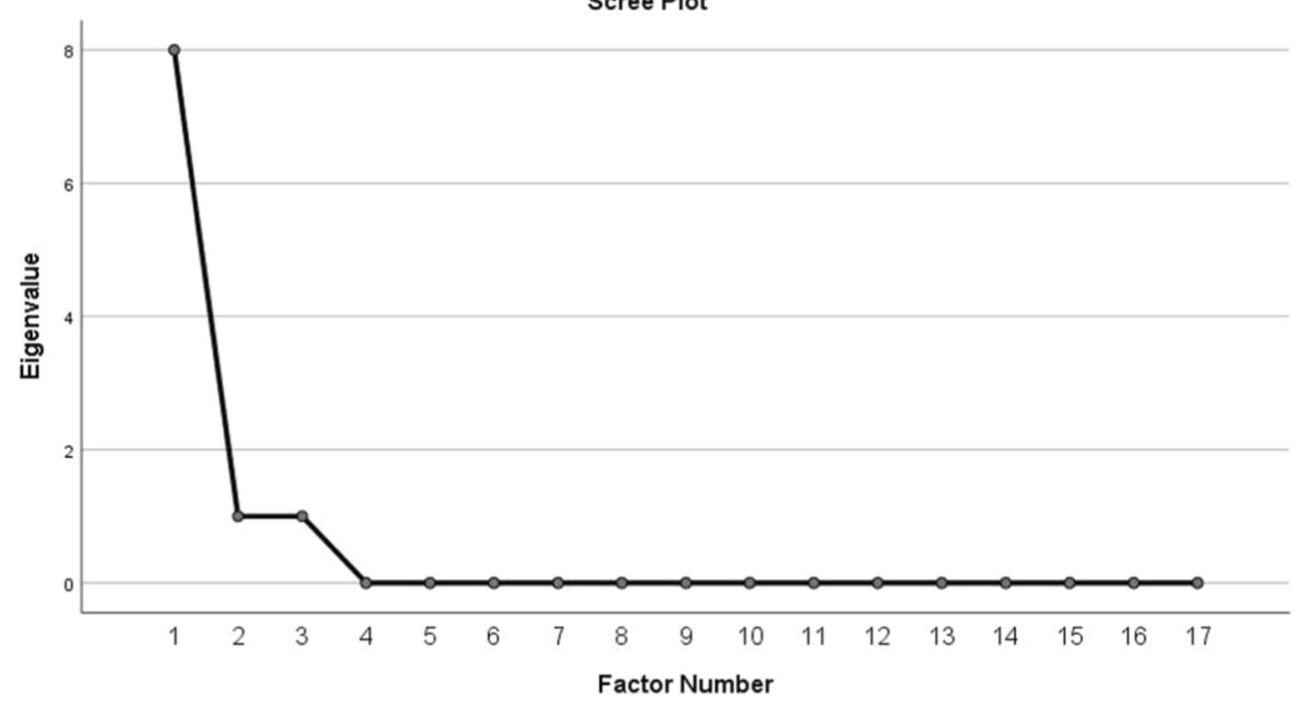

belittling her thoughts and interests, not showing her affection, belittling her appearance or clothing preferences, insulting her loved ones, ignoring her, or accusing her of laziness. Humiliation is a sort of verbal and mental violence that often remains hidden in the cultural structure of the society, and is not acknowledged in many societies. This type of violence affects the mental health of women more than physical violence, and undermines their self-actualization through destroying their self-esteem (Sohrabzadeh and Mansourian Ravandi 2017).

Mutual violence in which both partners are violent and aim to control each other is also more likely to occur during
Table 1 Results of exploratory factor analyses (EFA) of the Domestic Violence during Quarantine Scale (DVQS)

\begin{tabular}{|c|c|c|c|c|}
\hline Factors & Items & $\begin{array}{l}\text { Factor } \\
\text { loading }\end{array}$ & $\begin{array}{l}\% \\
\text { Variance }\end{array}$ & Eigenvalue \\
\hline \multirow[t]{7}{*}{$\begin{array}{c}\text { Factor } \\
1\end{array}$} & $\begin{array}{l}\text { 28. He has accused you of laziness, indifference, or not } \\
\text { performing your duties in terms of him or household } \\
\text { chores. }\end{array}$ & 0.867 & \multirow[t]{7}{*}{8.01} & \multirow[t]{7}{*}{8.010} \\
\hline & $\begin{array}{l}\text { 29. He has underestimated your ability to raise children, and } \\
\text { accused you of not being a successful mother or wife. }\end{array}$ & 0.763 & & \\
\hline & $\begin{array}{l}\text { 27. He has blamed you by belittling your thoughts and } \\
\text { interests. }\end{array}$ & 0.746 & & \\
\hline & $\begin{array}{l}\text { 22. He has not shown affection to you, so that you felt severe } \\
\text { loneliness. }\end{array}$ & 0.713 & & \\
\hline & $\begin{array}{l}\text { 30. He has belittled your clothes preferences, body, or } \\
\text { appearance. }\end{array}$ & 0.641 & & \\
\hline & 20. He has insulted your loved ones. & 0.635 & & \\
\hline & $\begin{array}{l}\text { 14. He has ignored you intentionally, or has refrained from } \\
\text { having sex with you for weeks. }\end{array}$ & 0.555 & & \\
\hline \multirow{6}{*}{$\begin{array}{c}\text { Factor } \\
2\end{array}$} & 12. He has threatened you with physical harm. & 0.913 & \multirow[t]{6}{*}{1.84} & \multirow{6}{*}{1.840} \\
\hline & 13. He has beaten you up (slapping, kicking, pulling hairs etc.) & 0.838 & & \\
\hline & 24. He has threatened you with divorce. & 0.772 & & \\
\hline & 26. He has thrown objects at you. & 0.741 & & \\
\hline & 11. He has insulted you in front of others. & 0.477 & & \\
\hline & $\begin{array}{l}\text { 8. He has been away from home days or weeks without } \\
\text { informing you. }\end{array}$ & 0.414 & & \\
\hline \multirow{4}{*}{$\begin{array}{c}\text { Factor } \\
3\end{array}$} & 18. He has not allowed you to eat or to choose your food. & 0.938 & \multirow[t]{4}{*}{1.10} & \multirow[t]{4}{*}{1.102} \\
\hline & 16. He has not allowed you to use telephone or social media. & 0.639 & & \\
\hline & $\begin{array}{l}\text { 17. He has not allowed you to choose your favorite TV } \\
\text { channel. }\end{array}$ & 0.518 & & \\
\hline & $\begin{array}{l}\text { 15. He has forced you to sexual intercourse when you were } \\
\text { not interested. }\end{array}$ & 0.485 & & \\
\hline
\end{tabular}


quarantine (Ali and McGarry 2019). Given that this type of violence is very rare, it can be ignored in this study. Separation-instigated violence occurs among couples who are on the brink of divorce (McKay et al. 2018); the time of their divorce may have coincided with the pandemic. Elevated stress, potential financial losses or job loss due to illness, and being quarantined during the COVID-19 pandemic, make couples, especially men who are often responsible for providing for their families, more vulnerable to show aggressive behaviors. Although violent behaviors tend to occur during crises, they have not been adequately examined. Some reports showed up to $46 \%$ increase in alcohol use, stress, and aggressive behaviors following the eruption of Mount St. Helens (Campbell 2020; Adams and Adams 1984). In addition, after Hurricane Katrina, mental violence against women increased by $35 \%$, and physical violence against them doubled. Moreover, significant increases in domestic violence were reported after the 2009 "Black Saturday" bushfires in Australia and the 7.0 magnitude earthquake in Haiti in 2010 (Campbell 2020; Schumacher et al. 2010). Given the nature of domestic violence during the COVID-19 pandemic, public policies in support of women in quarantine should be adopted (de Lima et al. 2020), and we should learn lessons from this pandemic that can help us better manage future crises. Victims of domestic violence and sexual abuse need to be provided with consultation, shelter, and 24-h hotlines. Similarly, in the Ebola virus disease epidemic in West Africa from 2014 to 2016, which led to strict quarantine measures, the rate of domestic violence increased (Evans et al. 2020).

In Hurricane Katrina, the rate of domestic violence increased from four cases per 100,000 per day to more than 16 cases per 100,000 per day among hurricane victims (Bell and Folkerth 2016). Despite the similarities between the COVID19 pandemic and other natural disasters, the closure of key organizations during this pandemic may take longer than during other natural disasters. In addition, during other natural disasters, people were urged to stay together, while during this pandemic, they are encouraged to stay away from each other; therefore, a higher increase in domestic violence is expected during this crisis compared to previous natural disasters (Campbell 2020). However, as after natural disasters, domestic violence during the COVID-19 pandemic may last for a long time, and may have lasting adverse effects on the mental health of victims (Hajnasiri et al. 2016).

This study had several limitations. Although the quarantine order was announced to the people by the government, the extent to which people complied with these measures was not the same, which could affect the reported violence. Some participants may also have been unable to provide accurate information about domestic violence for reasons such as their husbands controlling their phones. The link we sent to different groups of people was only active for a month, so it was not possible to collect more samples.

\section{Conclusion}

Overall, the Domestic Violence during Quarantine Scale (DVQS) has good validity and reliability and a proper number of items to assess domestic violence during quarantine, and can be used in future studies.

Abbreviations CVI, content validity index; DVQS, Domestic Violence during Quarantine Scale; EFA, exploratory factors analysis; KMO, Kaiser-Mayer-Olkin; VAWI, Violence Against Women instrument; WHO, World Health Organization

Acknowledgements The authors wish to thank the Vice-Chancellor of Research Affairs at the Shahid Beheshti University of Medical Sciences.

Author's contribution RGG and HZ contributed in design and performing study, SHE and AE conducted data analysis, KA and BM contributed to grammar editing.

Funding The present study was funded by the Shahid Beheshti University of Medical Sciences.

Availability of data and materials The datasets used and/or analysed during the current study are available from the corresponding author on reasonable request.

\section{Declarations}

Ethics approval and consent to participate The study objectives were explained to the participants and the participants were reassured that their personal information remained completely confidential.

Consent to publish Not applicable.

Competing interests The authors declare no competing interests.

\section{References}

Abuhammad S (2021) Violence against Jordanian women during COVID-19 outbreak. Intl J Clin Practice 75(3):e13824. https://doi. org/10.1111/ijcp.13824

Adams PR, Adams GR (1984) Mount Saint Helens's ashfall: evidence for a disaster stress reaction. Am Psychol 39(3):252. https://doi.org/10. 1037/0003-066X.39.3.252

Agüero JM (2021) COVID-19 and the rise of intimate partner violence. World Dev 137:105217. https://doi.org/10.1016/j.worlddev.2020. 105217

Ali P, McGarry J (2019). Domestic violence in health contexts: a guide for healthcare professions. Springer Nature, Switzerland. https://doi. org/10.1007/978-3-030-29361-1

Ansara DL, Hindin MJ (2010) Exploring gender differences in the patterns of intimate partner violence in Canada: a latent class approach. J Epidemiol Commun Health 64(10):849-854. https://doi.org/10. 1136/jech.2009.095208

Ansara DL, Hindin MJ (2011) Psychosocial consequences of intimate partner violence for women and men in Canada. J Interpers Violence 26(8):1628-1645. https://doi.org/10.1177/ 0886260510370600 
Azadarmaki T, Kassani A, Menati R, Hassanzadeh J, Menati W (2016) Psychometric properties of a screening instrument for domestic violence in a sample of Iranian women. Nursing Midwifery Stud 5(1): e27763. https://doi.org/10.17795/nmsjournal27763

Bell SA, Folkerth LA (2016) Women's mental health and intimate partner violence following natural disaster: a scoping review. Prehosp Disaster Med 31:648-652. https://doi.org/10.1017/ S1049023X16000911

Bolarinwa OA (2015) Principles and methods of validity and reliability testing of questionnaires used in social and health science researches. Nigerian Postgrad Med J 22(4):195-201. https://doi.org/ $10.4103 / 1117-1936.173959$

Bradbury-Jones C, Isham L (2020) The pandemic paradox: the consequences of COVID-19 on domestic violence. J Clin Nursing 29(1314):2047-2049. https://doi.org/10.1111/jocn. 15296

Campbell AM (2020) An increasing risk of family violence during the Covid-19 pandemic: strengthening community collaborations to save lives. Forensic Sci Intl Rep 2:100089. https://doi.org/10.1016/j. fsir.2020.100089

de Lima CA, Alves PMR, de Oliveira CJB, de Oliveira TRN, Barbosa $\mathrm{KB}$, Marcene HC et al (2020) Letter to the editor: COVID-19: isolations, quarantines and domestic violence in rural areas. Sci Med J 2(1):44-45. https://doi.org/10.28991/SciMedJ-2020-0201-7

DiIorio CK (2006). Measurement in health behavior: methods for research and evaluation. Jossey-Bass, San Francisco

Dunn TJ, Baguley T, Brunsden V (2014) From alpha to omega: a practical solution to the pervasive problem of internal consistency estimation. British J Psychol 105(3):399-412. https://doi.org/10.1111/ bjop. 12046

Evans DP, Hawk SR, Ripkey CE (2020) Domestic violence in Atlanta, Georgia before and during COVID-19. Violence Gender (ahead of print). https://doi.org/10.1089/vio.2020.0061

Ghahari S, Atefvahid M, Yousefi H (2006) The prevalence of spouse abuse among married students of Islamic Azad University of Tonekabon in 1383. J Mazandaran Univ Med Sci 15(50):83-89

Hajnasiri H, Ghanei Gheshlagh R, Karami M, Taherpour M, Khatooni M, Sayehmiri K (2017) Physical, sexual and emotional violence among Iranian women: a systematic review and meta-analysis study. Sci J Kurdistan Univ Med Sci 21(6):110-121

Hajnasiri H, Ghanei Gheshlagh R, Sayehmiri K, Moafi F, Farajzadeh M (2016) Domestic violence among Iranian women: a systematic review and meta-analysis. Iranian Red Cresc Med J 18(6):1-8. https:// doi.org/10.5812/ircmj.34971

Johnson MP (2006) Conflict and control: gender symmetry and asymmetry in domestic violence. Violence Against Women 12(11):10031018. https://doi.org/10.1177/1077801206293328

Kellar SP, Kelvin EA (2013). Munro's statistical methods for health care research. Wolters Kluwer Health/Lippincott Williams \& Wilkins, Philadelphia

Kelly JB, Johnson MP (2008) Differentiation among types of intimate partner violence: research update and implications for interventions. Fam Court Rev 46(3):476-499. https://doi.org/10.1111/j.17441617.2008.00215.x
Koziol-McLain J, Coates CJ, Lowenstein SR (2001) Predictive validity of a screen for partner violence against women. Am J Prevent Med 21(2):93-100. https://doi.org/10.1016/S0749-3797(01)00325-7

Lawshe CH (1975) A quantitative approach to content validity 1. Pers Psychol 28(4):563-575. https://doi.org/10.1111/j.1744-6570.1975. tb01393.x

Leslie E, Wilson R (2020) Sheltering in place and domestic violence: evidence from calls for service during COVID-19. J Pub Econ 189:104241. https://doi.org/10.1016/j.jpubeco.2020.104241

McKay TE, Lindquist CH, Landwehr J, Ramirez D, Bir A (2018) Postprison relationship dissolution and intimate partner violence: separation-instigated violence or violence-instigated separation? J Offender Rehab 57(5):294-310. https://doi.org/10.1080/10509674. 2018.1487898

Nunnally JC, Bernstein IH (1994) The theory of measurement error. Psycho Theory 3:209-247

Osborne JW (2008) Best practices in quantitative methods: Sage, Thousand Oaks, CA. https://doi.org/10.4135/9781412995627

Polit DF, Beck CT (2006) The content validity index: are you sure you know what's being reported? Critique and recommendations. Res Nursing Health 29(5):489-497. https://doi.org/10.1002/nur.20147

Schumacher JA, Coffey SF, Norris FH, Tracy M, Clements K, Galea S (2010) Intimate partner violence and hurricane Katrina: predictors and associated mental health outcomes. Violence Victims 25(5): 588-603. https://doi.org/10.1891/0886-6708.25.5.588

Sharif Nia H, Ebadi A, Lehto RH, Mousavi B, Peyrovi H, Chan YH (2014). Reliability and validity of the Persian version of Templer Death Anxiety Scale-Extended in veterans of Iran-Iraq warfare. Iran J Psych Behav Sci 8(4):29-37

Sohrabzadeh M, Mansourian Ravandi F (2017) Women's lived experience of verbal violence in the family (case study: women in Kashan). J Women Culture Arts 9(2):245-264. https://doi.org/10. 22059/JWICA.2017.234644.883

Vakili MM, Hidarnia AR, Niknami S (2012) Development and psychometrics of an interpersonal communication skills scale (ASMA) among Zanjan health volunteers. J Hayat 18(1):5-19

Waltz CF, Strickland OL, Lenz ER (2010). Measurement in nursing and health research: Springer publishing company

World Health Organization (2019) Coronavirus disease (COVID-19) pandemic. Country \& technical guidance - Coronavirus disease (COVID-19). World Health Organization, Geneva. https://www. who.int/emergencies/diseases/novel-coronavirus-2019/technicalguidance

World Health Organization (2005) WHO multi-country study on women's health and domestic violence against women: Initial results on prevalence, health outcomes and women's responses. World Health Organization, Geneva

Zhang H (2020). The influence of the ongoing COVID-19 pandemic on family violence in China. J Fam Violence 27:133-144. https://doi. org/10.1007/s10896-020-00196-8

Publisher's note Springer Nature remains neutral with regard to jurisdictional claims in published maps and institutional affiliations. 